Archivos de Ciencias de la Educación, Vol. 11, n 11, 2017, e026. ISSN 2346-8866

Universidad Nacional de La Plata.

Facultad de Humanidades y Ciencias de la Educación.

Departamento de Ciencias de la Educación.

\title{
Zemaitis, S. (2016). Pedagogf́as de la sexualidad. Antecedentes, conceptos e historia en el campo de la educación sexual de la juventud. Trabajo Final Integrador de Especialización en Nuevas Infancias y Juventudes, Facultad de Humanidades y Ciencias de la Educación, Universidad Nacional de La Plata
}

\section{Analís Escapil}

Universidad Nacional de La Plata, Argentina | a.escapil@gmail.com

Transitamos por múltiples espacios plagados de historias enredadas, y con historias propias que nos enredan; historias que nos construyen, historias que nos invaden, historias que nos expropian los cuerpos. ¿Cómo hemos habitado estos espacios? ¿Qué hemos aprendido? ¿Qué hemos desaprendido? ¿Qué ignorancias nos han atrapado? ¿Qué historias pueden contar nuestros cuerpos? ¿Cuáles han sido y cuáles son silenciadas? ¿Qué somos? ¿Cómo llegamos a serlo?

"Pedagogías de la sexualidad. Antecedentes, conceptos e historia en el campo de la educación sexual de la juventud” del Esp. Santiago Zemaitis constituye una obra que narra una historia y que nos des-narra. Nos invita a recorrer, explorar, indagar, aquellos caminos transitados formateando las 
palabras e invitando a los silencios silenciados a resonarse.

La escena que se propone recorrer es la escuela: escenario donde los protagonistas, su repertorio, su teatralización han estado históricamente leídos desde un boceto heteronormativo que anula la posibilidad de encarnar y representar otros personajes. A través de cinco apartados Zemaitis desarrolla una indagación conceptual y bibliográfica sobre la cuestión de la sexualidad juvenil y las diferentes perspectivas pedagógicas sobre la formación de la sexualidad.

La “Presentación” está constituida por una aproximación general a la problemática y por los objetivos que se persiguen. Aquíel/la lector/a encontrará una posible hoja de ruta para guiar su lectura. Luego, en la “Introducción”, el autor profundiza en la presentación de la temática a investigar, recuperando brevemente el célebre trabajo de Norbert Elias (1989) como puntapié inicial que permite enmarcar el interés del autor por la temática propuesta y su relevancia, problematizando las mutaciones en las pautas de comportamiento a lo largo de la historia, que han regulado (y regulan) los procesos de subjetivación, el tratamiento de la sexualidad, los cuerpos, la infancia, la juventud, la adultez, entre otros. Se comienzan a visualizar en este apartado los silencios que han sido configurados, atrapados históricamente en la educación sexual como práctica social.

En este sentido, Zemaitis (2016) define a la educación sexual como un "campo polisémico compuesto por formaciones discursivas diversas en el cual se articulan, superponen y enfrentan distintos enunciados que provienen de distintos discursos sociales” (p. 6). No obstante, de este universo posible de prácticas discursivas sobre la educación sexual, el autor focaliza en el discurso pedagógico escolar de la educación sexual y puntualmente aquel que tenga como protagonista a la juventud.

En el primer apartado presenta un recorrido por investigaciones y estudios que tienen como objeto de análisis las relaciones entre educación, sexualidad, género y juventudes. Recupera allí aportes de la investigación pedagógica, la historia social y la antropología y sociología de la juventud, enmarcando las mismas en un contexto más amplio de investigación social sobre la sexualidad juvenil o adolescente, iniciada en la década del 70 en el caso argentino.

Desde la investigación pedagógica, recupera diversos estudios desarrollados tanto en el ámbito nacional como internacional, haciendo alusión a producciones de investigadores provenientes de Australia, Brasil, Estados Unidos, Reino Unido, Uruguay, Ecuador y Argentina. El recorrido que realiza Zemaitis por estas investigaciones y estudios, permite "comprender a las instituciones educativas como espacios que producen y reproducen representaciones e imágenes normativas del género y regulación sobre las identidades sexuales” (p. 12). También, desde distintos interrogantes y guiados por distintas temáticas de investigación, los estudios que recupera el autor contribuyen a problematizar los diferentes dispositivos, prácticas, saberes, rituales que han configurado los cuerpos "masculinos" y "femeninos" en el espacio escolar, y esos otros cuerpos que no se ajustan a la norma.

Los aportes desde la historia social que recupera Zemaitis, vienen de la mano de las investigaciones de las argentinas Graciela Queirolo (2013); Marcela Nari (2004); Karina Felitti (2009, 2012); Isabella Cose y Valeria Manzano (2010); y del argentino Juan Cruz Esquivel (2013). Estos trabajos aportan una sistematización de los sentidos, prácticas y discursos en torno a las políticas y 
propuestas educativas y escolares de educación sexual en Argentina. Permiten rastrear y problematizar las disputas y negociaciones entre distintos actores relevantes en la definición de políticas de educación sexual a lo largo de la historia en Argentina: Estado, iglesia católica, familia, movimientos feministas, entre otros.

Por último, y como cierre de este apartado, los aportes desde la sociología y la antropología que tienen como objeto de estudio a la juventud, Zemaitis dialoga con las investigaciones de Mario Margulis (2003); Daniel Jones (2009, 2010); Mariana Chaves (2006, 2009, 2011) y Silvia Elizalde (2006, 2011). Los estudios realizados por estos/as autores/as, recuperan la indagación por temáticas que usualmente se mantienen silenciadas en el trabajo en diálogo con la juventud: masturbación, pornografía, diálogos y silencios con los pares y padres, chismes que circulan, entre otros. Permiten advertir una concepción de la juventud desde el discurso de la patología social, que motoriza y articula las políticas y propuestas educativas y escolares de educación sexual destinadas a los/as jóvenes, haciendo énfasis en la prevención de enfermedades y embarazos como contenidos centrales a trabajar. La juventud es significada como el "pedazo" de la sociedad que está enfermo, estableciendo una única forma de ser joven, que es ciega a los atravesamientos de clase, género, etnia.

En el segundo apartado, el autor avanza en el abordaje de los referentes conceptuales que orientan su investigación: sexualidad, identidad y pedagogías de la sexualidad. Zemaitis parte de una perspectiva socioconstructivista para conceptualizar la sexualidad, es decir, “...entenderla como dimensión humana, que más que explicarse biológicamente - en términos universales y homogéneos- ésta es concebida como una manifestación condicionada y moldeada por cada cultura y por cada tiempo histórico, a partir de sus significaciones morales, sus tabúes, sus reglamentos, administraciones y controles” (p.18). Los desarrollos teóricos de Michel Foucault (2008, 2011), Jeffrey Weeks (2012), Guacira Lopes Louro (1999) y Esther Díaz (2014), le permiten a Zemaitis advertir los diversos y variables modos de aprender y construir la sexualidad, y la posibilidad de deconstruir aquellas prácticas sociales que generan “dominios deseantes” en una época determinada.

En relación al referente conceptual “identidad” el autor realiza un cruce interesante entre sexualidad, identidad y género para su desarrollo. El autor intenta romper con una tradición "biologizante” y esencialista de conceptualizar la identidad a partir de rasgos o características individuales. La identidad tiene que ver con las maneras en que nos relacionamos con los demás. En este sentido, el autor recupera una diferencia conceptual desarrollada por Lopes Louro (1999) sobre identidades sexuales e identidades de género. Si bien ambas identidades son construcciones móviles, cambiantes y relacionadas temporalmente con las experiencias de vida de cada sujeto,

las identidades sexuales se constituyen a partir de las formas de cómo las personas viven la sexualidad (con personas del mismo sexo, de ambos sexos o de otro sexo), las identidades de género hacen referencia a las identificaciones, que social e históricamente hacen los sujetos sobre lo femenino y masculino (Zemaitis, 2016, p. 20).

Para dar cierre a este apartado, el autor profundiza sobre las pedagogías de la sexualidad desde una mirada histórica, con la intencionalidad de desarmar modelos y problematizar las concepciones 
sobre la sexualidad que sostienen y la propuesta de educación sexual que intentan llevar adelante. La caracterización de distintas corrientes pedagógicas sobre la sexualidad, le permiten al autor deconstruir, desarmar, desagregar sentidos sobre los discursos en el campo de la educación sexual. No conforman modelos puros o estancos, sino que se encuentran relacionados, en interdependencia, conviviendo en la práctica. Estas pedagogías o corrientes planteadas son la concepción moralista, la biologicista, la patologista o del riesgo y, por último, se detiene especialmente en el denominado paradigma de los derechos y la integralidad como perspectiva.

En este último caso, se enfatiza una concepción de sexualidad que trasciende lo orgánico, genital, biológico, y se la entiende como una construcción social, histórica y política. Estos discursos, conciben a los/as jóvenes como sujetos de derecho, que deben poder desarrollar una sexualidad libre en la que se considera el placer, el deseo y el conocimiento del propio cuerpo. Desde este enfoque, se promueven propuestas pedagógicas de educación sexual que comprendan a los/as jóvenes como poseedores/as de saberes previos en materia de sexualidad que toda intervención educativa debe reconocer y recuperar.

Para finalizar este apartado, Zemaitis recupera los trabajos de Alejandro Villa (2009); Guacira Lopes Louro (1999) y Deborah Britzman (2002) como estudios de referencia en el avance de otros modelos de educación sexual. Estos desarrollos permiten ampliar la mirada y el abordaje institucional de las cuestiones ligadas a la sexualidad. Problematizan temáticas como la autoridad docente en torno a las cuestiones de la sexualidad, la transversalidad en el abordaje de la temática, la deconstrucción de un discurso binario de los cuerpos que se refuerza en los contenidos escolares, entre otros.

En el tercer apartadoel autor realiza una reseña histórica sobre hechos e iniciativas (oficiales y privadas) asociados a laeducación sexual en Argentina desde inicios del siglo XX hasta la actualidad. Recuperando puntualmente las investigaciones de Abril Lavrin (2005) y Marcela Nari (2004), Zemaitis afirma que a principios del siglo XX, las propuestas de educación sexual se motorizaron bajo una matriz generizada, iniciativas diferentes para varones y mujeres, materializadas en espacios curriculares como "Puericultura” “Tareas Domésticas” por ejemplo. En este período, y a partir de la problemática social de la expansión de las enfermedades venéreas, se formularon desde el Estado propuestas de educación sexual bajo la impronta de la profilaxis social, en diálogo con las corrientes médico-políticas del higienismo y eugenismo social.

Como hechos centrales en la primera mitad del siglo XX, el autor destaca la creación de la Liga de Profilaxis Social, fundada en 1921, desde la cual se llevaron adelante distintas propuestas en planos formales e informales; y la sanción en 1936 de la Ley de Profilaxis de las Enfermedades Venéreas, "primera iniciativa legislativa nacional con intenciones de que la educación sexual se vuelva parte del curriculum en las escuelas” (Zemaitis, 2016, p.38). Ambos hechos, tuvieron a las enfermedades venéreas como el centro de atención.

A mediados del siglo XX, entre las décadas de 1950 a 1970, y en relación a acontecimientos surgidos en un plano internacional, comenzó a gestarse un nuevo paradigma sobre las concepciones sobre sexualidad, y con ello una nueva mirada de la educación sexual. Entre los hechos que el autor menciona, se pueden destacar, la irrupción de los jóvenes en la escena pública, la masificación de la educación secundaria que propicia nuevos espacios y dinámicas de relaciones entre los jóvenes, 
circulación de temas sobre sexualidad en industrias culturales y medios masivos, desarrollo de la Sexología como disciplina, difusión de la teoría psicoanalítica, entre otros. No obstante, no se identifican en el período políticas de educación sexual promocionadas desde el Estado de largo plazo. Los gobiernos dictatoriales de mediados de siglo interrumpieron estos avances, reafirmando valores morales católicos y perspectivas pro natalistas. Por lo tanto, las propuestas de educación sexual fueron desarrolladas más bien por entidades privadas y provenientes de las áreas de la psicología y medicina.

Por el contrario, la década del 80 y el contexto de apertura democrática presentó un escenario propicio para el desarrollo de políticas de educación sexual desde el Estado. "Desde esta década en adelante en Argentina se fueron sucediendo distintos avances legislativos sobre la sexualidad y la vida reproductiva” (Zemaitis, 2016, p. 43). Se pueden mencionar a modo de ejemplo: la sanción en 1990 de la Ley Nacional de SIDA (23.798); la reforma de la Carta Magna en 1994 que incorpora a la Constitución Nacional tratados internacionales, y entre ellos la Declaración de los Derechos Humanos en referencia a los Derechos Reproductivos y Sexuales; Ley Nacional 25.673 de creación del Programa Nacional de Salud Sexual y Procreación Responsable, sancionada en el año 2002; inclusión de temáticas sobre sexualidad de forma transversal en los CBC (Contenidos Básicos Comunes) en el marco de las reformas educativas entre los años 1989-1999; avances en materia legislativa a nivel de las jurisdicciones provinciales como la ley de educación sexual sancionada en 1992 en Santa Fe, en 1994 en Mendoza, entre otros.

Con este recorrido en materia legislativa, Zemaitis reconoce un hecho central en la sanción de políticas sobre educación sexual en Argentina: la sanción de la Ley 26.150, ley de Educación Sexual Integral, sancionada en octubre del 2006. La sanción de esta ley supuso un cambio de paradigma sobre “cómo se concibe la sexualidad en el ámbito escolar y en la formación docente, las relaciones entre los géneros y el derecho a todos los niños, niñas, jóvenes y adultos a recibir educación sexual en el sistema educativo oficial y como proyecto institucional en cada escuela” (p. 46).

El autor enmarca la sanción de la ley en un contexto más amplio de política educativa iniciado en el año 2003 bajo la presidencia de Néstor Kirchner (2003-2007) y que continuó con las dos presidencias de Cristina Fernández de Kirchner (2007-2015). Se identifica en este período una ampliación del rol del Estado, reconociendo como avances en materia legislativa la ley de Identidad de Género (26.743); la ley de Matrimonio Civil entre parejas del mismo sexo (26.618); la ley de Prevención y sanción de la trata de personas y asistencia a sus víctimas (26.364), entre otros.

El último apartado del trabajo aquí reseñado comprende conclusiones y aperturas, que se desligan de la intención de cerrar y finalizar este recorrido, sino que invitan a tomar las preguntas y la problematización como motores en la producción de teorías que nos permitan otras lecturas de lo que sucede en el mundo en general, y en la escena educativa en particular, avances que construyan aquellos cimientos necesarios para construir una pedagogía de la sexualidad socialmente relevante.

En este sentido, el autor plantea cinco líneas para seguir trabajando. En primer lugar, continuar con la indagación histórica sobre la educación sexual en el espacio escolar, recuperando temáticas poco exploradas como, por ejemplo, discursos sobre el SIDA, construcción escolar del par salud/enfermedad entre otros. En segundo término, avanzar en una perspectiva pedagógica 
superadora de la biologización de la sexualidad y su enseñanza, donde “...se reconozca a los sujetos de la educación como "sujetos sexuados" y no a la juventud vista como un grupo incontrolable, promiscuo o peligroso” (Zemaitis, 2016, p.53). En tercer lugar, pensar una pedagogía de la sexualidad distinta a cómo se la ha concebido hasta la actualidad donde se realice un "pasaje de una moral sexual a una ética sexual” (p. 54). En cuarto, lugar, indagar sobre los actuales procesos de socialización de las juventudes, y construir los espacios necesarios para su trabajo. Y finalmente, revolucionar los vínculos pedagógicos, habilitando y habitando las preguntas como motores para la construcción del conocimiento con otros/as.

Para concluir este recorrido, se puede afirmar que la producción realizada por Zemaitis se aventura en la escritura de una obra que re escribe la historia de la educación sexual de la juventud en la escena educativa. Convoca a una multiplicidad de voces que motorizan dispositivos que funcionan como amplificadores de aquellas historias jamás contadas, de aquellos/as nosotros/as jamás historizados/as, de aquella escena escolar escondida en los telones de la norma.

\section{Bibliografía}

Britzman, D. (2002). La pedagogía transgresora y sus extrañas técnicas. En Mérida Jiménez, R. (Ed.) Sexualidades transgresoras. Una antología de estudios queer. Barcelona: Icaría.

Chaves, M. (2006). Construyendo ciudadanía: tres acontecimientos para leer juventudes, prácticas culturales y políticas del estado. Actas de las IV Jornadas de Sociología de la UNLP: la Argentina de la crisis. Desigualdad social, movimientos sociales, política e instituciones, Argentina.

Cosse, I., Felitti, K. y Manzano, V. (2010). Los '60 de otra manera. Vida cotidiana, género y sexualidades en la Argentina. Buenos Aires: Siglo XXI.

Elias, N. (1989). El proceso de la civilización. Investigaciones sociogenéticas y psicogenéticas. México: Fondo de Cultura Económica.

Elizalde, S. (2006). El androcentrismo en los estudios de juventud: efectos ideológicos y aperturas posibles.Revista Última Década, vol.14 (25).

Elizalde, S. (Comp.) (2011). Jóvenes en cuestión. Configuraciones de género y sexualidad en la cultura. Buenos Aires: Biblos.

Felitti, K. (2009). Difundir y controlar. Iniciativas de educación sexual en los años sesenta. Revista argentina de estudios de juventud, Vol.1, (1).

Felitti, K. (2012). La revolución de la píldora: sexualidad y política en los sesenta. Buenos Aires: Edhasa.

Foucault, M. (2008). Historia de la sexualidad. La voluntad del saber. Buenos Aires: Siglo XXI.

Foucault, M. La inquietud de sí. Escritos sobre la sexualidad y el sujeto. Buenos Aires: Siglo XXI.

Jones, D. (2009). ¿De qué hablamos cuando hablamos de sexualidad? Educación sexual en escuelas 
de nivel secundario antes de la Ley de Educación Sexual Integral de la Argentina. Argumentos. Revista de Crítica Social (11) 63-82.

Lavrin, A. (2005). Mujeres, feminismo y cambio social en Argentina, Chile y Uruguay 189-1940. Buenos Aires: Fondode Cultura Económica.

Lopes Louro, G. (1999). O corpo educado. Pedagogias da sexualidade. Belo Horizonte: Autêntica. Margulis, M. (2003). Juventud, cultura, sexualidad. Buenos Aires: Biblos.

Nari, M. (2004). Políticas de maternidad y maternalismo político. Buenos Aires (1890-1920). Buenos Aires: Biblos.

Queirolo, G. (2013). Género y sexualidades en tiempos de males venéreos (Buenos Aires, 19201940). Revista Nomadías, n 17 , Julio, 67-87.

Villa, A. (2007). Cuerpo, sexualidad y socialización. Intervenciones e investigaciones en salud y educación. Buenos Aires: Novedades Educativas.

Villa. A. (2009). Cuerpo, relaciones de género y de generación: perspectivas biográficas e históricoculturales en el campo de la educación. En Villa, A. (Comp.) Sexualidad, relaciones de género y de generación. Perspectivas histórico-culturales en educación. Buenos Aires: Noveduc.

Weeks, J. (2012). Lenguajes de la sexualidad. Buenos Aires: Nueva Visión.

Zacarías, N. (2011). La educación sexual en las políticas educativas latinoamericanas recientes. Un aporte desde los estudios de género. Actas del IV Coloquio Internacional Interdisciplinario: educación, sexualidades y relaciones de género. Investigaciones, experiencias y relatos, Argentina.

Zemaitis, S. (2016). Pedagogías de la sexualidad. Antecedentes, conceptos e historia en el campo de la educación sexual de la juventud. (Trabajo Final Integrador de Especialización). Recuperado de Memoria Académica: http://www.memoria.fahce.unlp.edu.ar/library?a=d\&c=tesis\&d=Jte1218 